\title{
Genetic Evidence for a Contribution of EphA:EphrinA Reverse Signaling to Motor Axon Guidance
}

\author{
Irina Dudanova, ${ }^{1}$ Tzu-Jen Kao, ${ }^{2}$ Julia E. Herrmann, ${ }^{3}$ Binhai Zheng, ${ }^{3}$ Artur Kania, ${ }^{2,4,5}$ and Rüdiger Klein ${ }^{1}$ \\ ${ }^{1}$ Department of Molecular Neurobiology, Max Planck Institute of Neurobiology, Am Klopferspitz 18, 82152 Martinsried, Germany, ${ }^{2}$ Institut de Recherches \\ Cliniques de Montréal, Montréal, Québec H2W 1R7, Canada, ${ }^{3}$ Department of Neurosciences, University of California San Diego, La Jolla, California \\ 92093-0691, ${ }^{4}$ Departments of Anatomy and Cell Biology, and Biology, Division of Experimental Medicine, McGill University, Montréal, Québec H3A 2B2 \\ Canada, and ${ }^{5}$ Faculté de Médecine, Université de Montréal, Montréal, Québec H3C 3J7 Canada
}

Repulsive Eph forward signaling from limb-derived ephrins guides the axons of lateral motor column (LMC) motor neurons. LMC axons also express ephrinAs, while their EphA receptors are expressed in the limb mesenchyme. In vitro studies have suggested that reverse signaling from limb-derived EphA4 to axonal ephrinAs might result in attraction of LMC axons. However, genetic evidence for this function is lacking. Here we use the Dunn chamber turning assay to show that EphA proteins are chemoattractants and elicit fast turning responses in LMC neurons in vitro. Moreover, ectopic expression of EphA4 in chick hindlimb changes the limb trajectory of LMC axons. Nervous system-specific deletion of EphA4 in mice resulted in fewer LMC axon projection errors than the ubiquitous deletion of EphA4. Additionally, a signaling-incompetent EphA4 mutant partially rescued guidance errors in the hindlimb, suggesting that limb-derived EphA4 contributes to the establishment of LMC projections. In summary, we provide evidence for a role of EphA:ephrinA attractive reverse signaling in motor axon guidance and in vivo evidence of in-parallel forward Eph and reverse ephrin signaling function in the same neuronal population.

\section{Introduction}

The establishment of a precise map of neuronal connections during development depends on the navigational decisions made by growing axons with the help of guidance cues in their environment (Dickson, 2002). Among the prominent molecular players implicated in axonal pathfinding are Eph receptor tyrosine kinases and their ephrin ligands, whose interactions can lead to bidirectional signaling. Activation of Eph receptors results in "forward" signaling events within the Eph-expressing cell, while membrane-attached ephrin ligands trigger "reverse" signaling responses within the ephrin-expressing cell (Egea and Klein, 2007). Eph and ephrin coexpression on the same neurons as well as in vitro experiments suggest that forward and reverse signaling can function in parallel and direct axonal pathway selection. However, a genetic in vivo test of such dual function remains elusive.

Motor axon projections to the hindlimb represent a convenient and well established system to study ephrin:Eph signaling. Limb-innervating motor neurons are situated in the spinal cord within the lateral motor column (LMC). The laterally positioned $\left(\mathrm{LMC}_{\mathrm{L}}\right)$ neurons innervate dorsal limb muscles, while the medi-

\footnotetext{
Received Nov. 14, 2011; revised Feb. 8, 2012; accepted Feb. $27,2012$.

Author contributions: I.D., A.K., and R.K. designed research; I.D. and T.-J.K. performed research; J.E.H. and B.Z. contributed unpublished reagents/analytic tools; I.D. and T.-J.K. analyzed data; I.D., A.K., and R.K. wrote the paper.

This study was supported by the Max Planck Society, the Deutsche Forschungsgemeinschaft (Grant SFB870), the German-Israeli Foundation, and Canadian Institutes of Health Research (Grant MOP-77556). We thank L. Loschek for preliminary experiments in the early stage of the project; T. Marquardt, A. Huber-Brösamle, and E. Bianchi for help with establishing techniques; J. Lindner and M. Liang for technical assistance; D. Marinescu and S. Krinner for mouse genotyping; A. Huber-Brösamle for the Lim1 antibody; and G. Gatto for discussions.

Correspondence should be addressed to Rüdiger Klein, Department of Molecular Neurobiology, Max Planck Institute of Neurobiology, Am Klopferspitz 18, 82152 Martinsried, Germany. E-mail: rklein@neuro.mpg.de.

DOI:10.1523/JNEUROSCI.5707-11.2012

Copyright $\odot 2012$ the authors $\quad 0270-6474 / 12 / 325209-07 \$ 15.00 / 0$
}

ally positioned $\left(\mathrm{LMC}_{\mathrm{M}}\right)$ neurons innervate ventral limb muscles (Landmesser, 1978). The canonical model of LMC axon guidance involves EphA4-expressing $\mathrm{LMC}_{\mathrm{L}}$ axons being repelled from ephrinAs in the ventral limb. Deletion of EphA4 in mice leads to ventral rerouting of $\mathrm{LMC}_{\mathrm{L}}$ axons (Helmbacher et al., 2000), a phenotype attributed to the lack of repulsion from ephrinAs. Conversely, ectopic expression of EphA4 in chick $\mathrm{LMC}_{\mathrm{M}}$ causes misprojections of $\mathrm{LMC}_{\mathrm{M}}$ axons into the dorsal nerve, confirming that EphA4 forward signaling in motor axons is important for the dorsal trajectory selection (Eberhart et al., 2002; Kania and Jessell, 2003).

In addition to its expression in $\mathrm{LMC}_{\mathrm{L}}$ axons, EphA4 is present in dorsal limb mesenchyme, while ephrinAs are also detected in LMC neurons (Iwamasa et al., 1999; Eberhart et al., 2000; Marquardt et al., 2005). In vitro, EphAs and ephrinAs on $\mathrm{LMC}_{\mathrm{L}}$ axons do not interact in cis, and can signal independently (Marquardt et al., 2005). Since ephrinA reverse signaling leads to increased axon growth (Marquardt et al., 2005; Kao and Kania, 2011), the presence of EphA4 in the limb mesenchyme suggests that attractive reverse signaling from EphA4 in the dorsal limb to axonal ephrinAs could contribute to $\mathrm{LMC}_{\mathrm{L}}$ axon guidance. However, a role of mesenchymal EphA4 in dorsal pathway selection in vivo remains to be demonstrated. Here we show that EphA proteins act as chemoattractants for $\mathrm{LMC}_{\mathrm{L}}$ axons in an in vitro turning assay and upon ectopic overexpression in vivo. The role of endogenous mesenchymal EphA4 as an attractive cue for LMC axons can be uncovered when EphA4 forward signaling in the axons is eliminated. Our results indicate that attractive EphA:ephrinA reverse signaling contributes to limb motor axon pathfinding.

\section{Materials and Methods}

Animals. Hb9-GFP, Prx1-cre, Nestin-cre, PGK-cre, EphA4 $4^{1 x}, E p h A 4^{E G F P}$, and EphA4 knock-out mice have been described previously (Lallemand et al., 1998; Tronche et al., 1999; Kullander et al., 2001; Logan et al., 2002; 
A

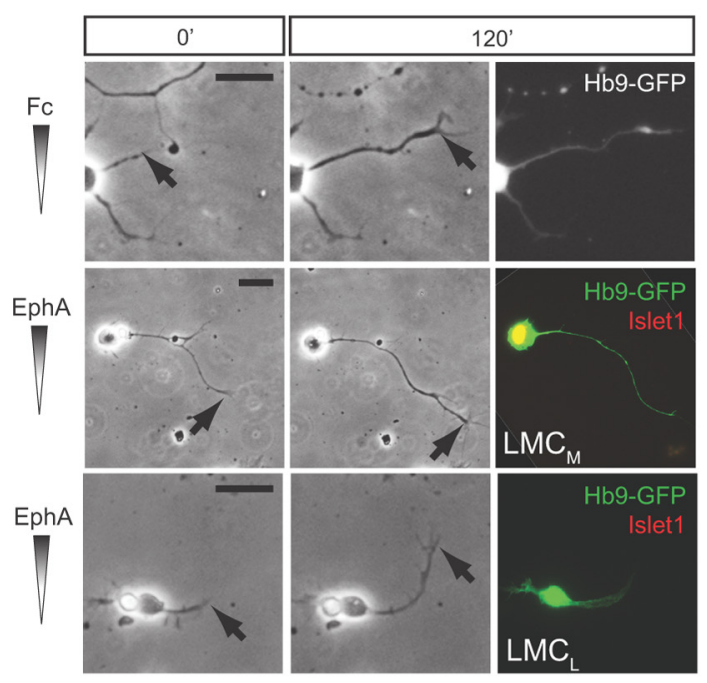

B


C

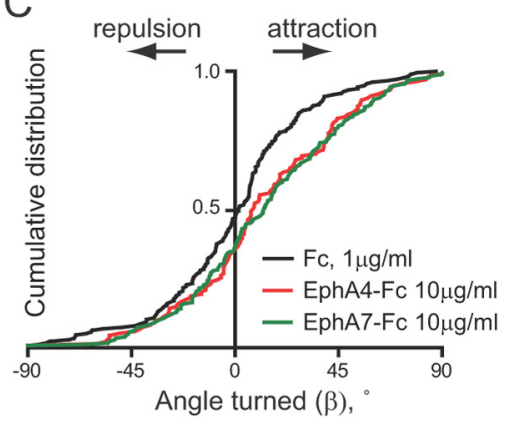

E

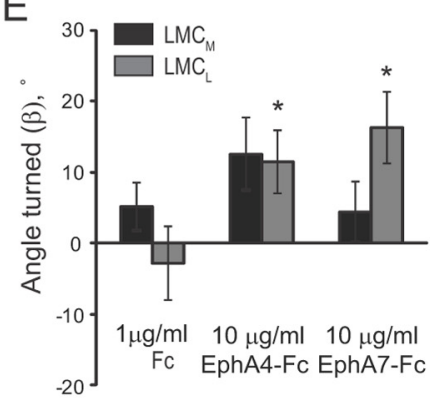

$\mathrm{F}$

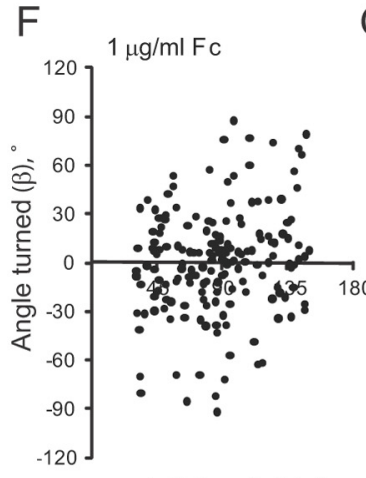

Initial angle $(\alpha)$,
G

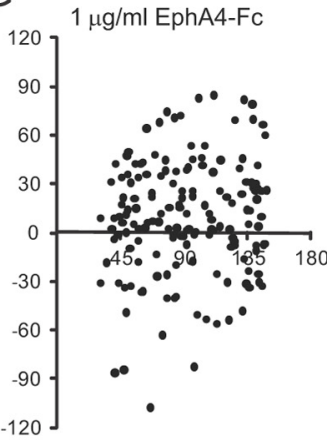

Initial angle $(\alpha)$,
$\mathrm{H}$

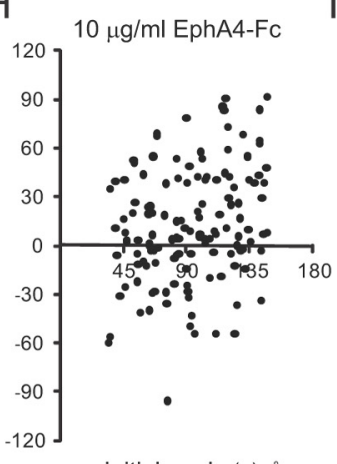

I

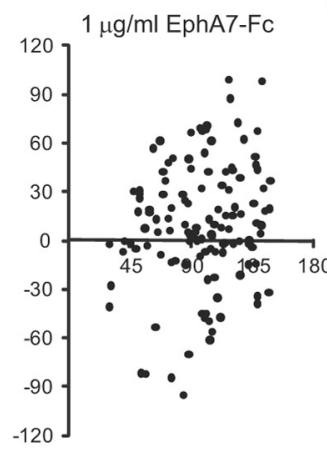

Initial angle $(\alpha)$ 。

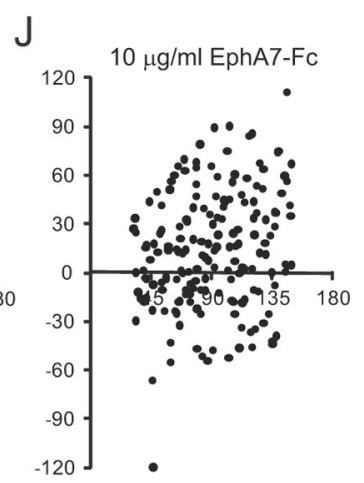

Initial angle $(\alpha)$,
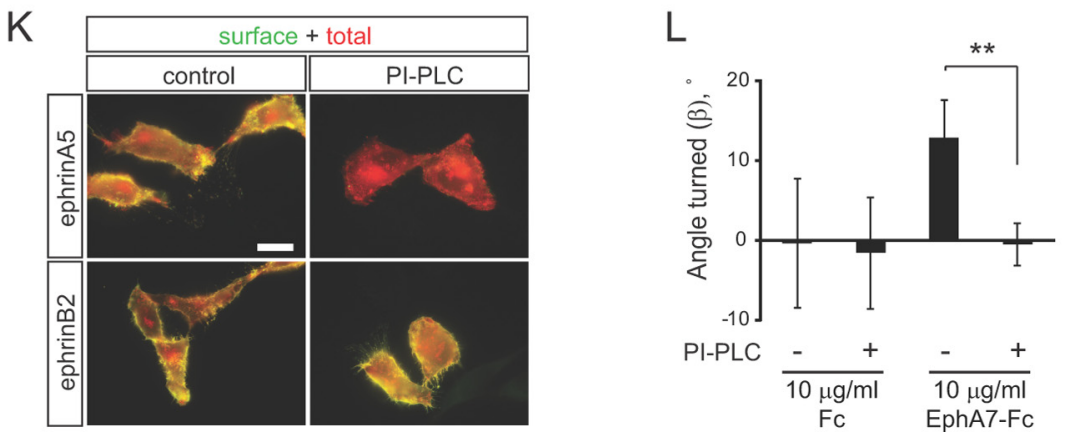

Figure 1. EphAs induce attractive turning of LMC axons. A, Representative examples of $H 69-G F P^{+} L M C$ neurons in indicated gradients at the beginning of the assay $\left(0^{\prime}\right)$ and after $2 \mathrm{~h}$ $\left(120^{\prime}\right)$. All images were aligned so that the gradient increases up the $y$-axis. Arrows point to the axon tip. Neurons were stained for Islet 1 after the assay (note yellow nucleus in $\mathrm{LMC}_{M}$ neuron). Scale bars, $20 \mu \mathrm{m} . \boldsymbol{B}, \boldsymbol{C}$, Graphs showing means \pm SEM $(\boldsymbol{B})$ and cumulative distributions $(\boldsymbol{C})$ of turning angles $(\beta)$ of $L M C$ axons in the indicated gradients. The numbers of axons analyzed are as follows: $\mathrm{Fc}, 175$ axons/8 cultures; $1 \mu \mathrm{g} / \mathrm{ml}$ EphA4-Fc, 160 axons/11 cultures; $10 \mu \mathrm{g} / \mathrm{ml}$ EphA4-Fc, 134 axons/8 cultures; $1 \mu \mathrm{g} / \mathrm{ml}$ EphA7-Fc, 123 axons/8 cultures; 10 $\mu \mathrm{g} / \mathrm{ml}$ EphA7-Fc, 177 axons/8 cultures. ${ }^{*} p<0.05,{ }^{* *} p<0.01,{ }^{* * *} p<0.001$, all conditions are compared with Fc. $D$, Quantification of the speed of axon growth in the indicated gradients. None of the differences are significant. $E$, Turning responses of $L M C_{M}$ and $L M C_{L}$ neurons in the indicated gradients. Numbers of axons analyzed: $F C_{\text {, }} 93 \mathrm{LMC} C_{M}$ and $34 \mathrm{LMC}_{\mathrm{L}}$ axons/8 cultures; $10 \mu \mathrm{g} / \mathrm{ml}$ EphA4-Fc, $58 \mathrm{LMC}_{\mathrm{M}}$ and $35 \mathrm{LMC}_{\mathrm{L}}$ axons/8 cultures; $10 \mu \mathrm{g} / \mathrm{ml}$ EphA7- $\mathrm{Fc}, 67 \mathrm{LMC}_{\mathrm{M}}$ and $45 \mathrm{LMC}_{\mathrm{L}}$ axons/8 cultures. ${ }^{*} p<0.05$, compared with the same population in $\mathrm{Fc}$ gradient. All the values are included in the quantification in $\boldsymbol{B}$ and $\boldsymbol{C}$. $\boldsymbol{F}-\boldsymbol{J}$, Scatter plots of the angle turned $(\beta)$ versus initial angle $(\alpha)$ for the indicated conditions. $\boldsymbol{K}$, Examples of HeLa cells transfected with HA- and mCherry-tagged ephrin constructs and immunostained for HA without permeabilization to detect the surface population of ephrins. $\mathrm{mCherry}$ autofluorescence shows the total ephrin protein. Treatment with PI-PLC completely removes the surface population of GPI-anchored ephrinA5, but not transmembrane ephrinB2. Scale bar, $20 \mu \mathrm{m}$. L, Quantification of LMC turning responses with and without PI-PLC treatment. Numbers of axons analyzed: Fc, 19 axons/ 1 culture; Fc with PI-PLC, 33 axons/2 cultures; EphA7-Fc, 47 axons/3 cultures; EphA7-Fc with PI-PLC, 89 axons/ 4 cultures. ${ }^{* *} p<0.01$. 
A

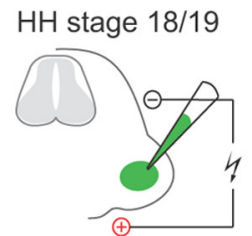

HH stage 28/29

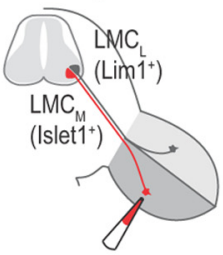

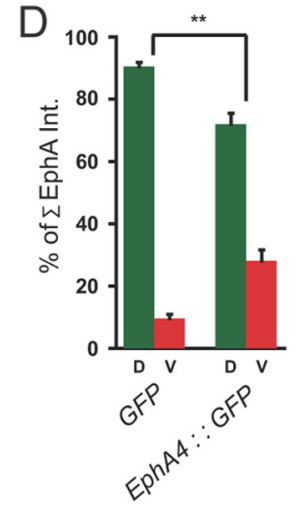


Figure 2. Ectopic expression of EphA4 in the ventral limb reroutes $L M C_{\perp}$ axons. $A$, Scheme of chick in ovo electroporation and retrograde tracings. $B, C$, Detection of GFP (green) and neurofilament (NF, red) in the hindlimb of chick HH stage 23/24 embryos electroporated with GFP $(\boldsymbol{B})$ or EphA4::GFP (C). Stippled boxes indicate the region of bifurcation of dorsal and ventral nerves, shown at a higher magnification in the middle and right panels. $\boldsymbol{B}^{\prime}, \boldsymbol{C}^{\prime}$, detection of free EphAs by ephrinA5-Fc overlay. Arrows in $\boldsymbol{C}^{\prime}$ point to patches of ectopic EphA4. $\boldsymbol{B}^{\prime \prime}, \boldsymbol{C}^{\prime \prime}$, detection of free ephrinAs by EphA4-Fc overlay. Scale bars: $\boldsymbol{B}, \boldsymbol{C}, 300 \mu \mathrm{m} ; \boldsymbol{B}^{\prime}, \boldsymbol{B}^{\prime \prime}, \boldsymbol{C}^{\prime}, \boldsymbol{C}^{\prime \prime}, 150$ $\mu \mathrm{m} . \boldsymbol{D}, \boldsymbol{E}$, Quantification of expression of free EphAs and free ephrinAs in GFP- or EphA4::GFP-electroporated embryos. $n=4$ embryos. ${ }^{* *} p<0.01$. n.s., Not significant. $\boldsymbol{F}, \mathbf{G}$, Detection of HRP and Lim1 in the LMC of chick embryos electroporated with GFP or EphA4::GFP and injected with HRP into the ventral shank. Examples of $\operatorname{Lim} 1{ }^{+} L M C_{L}$ neurons labeled with HRP are indicated by arrows and arrowheads. Cell marked by arrowhead is shown at higher magnification ( $\left(\mathbf{G}, \mathbf{G}^{\prime}\right.$, insets). Scale bars: $\boldsymbol{F}_{\mathbf{F}} \boldsymbol{F}^{\prime}, \mathbf{G}, \mathbf{G}^{\prime}, 35 \mu \mathrm{m}$; $\mathbf{G}, \boldsymbol{G}^{\prime}$, insets, $8 \mu \mathrm{m}$. $\boldsymbol{H}$, Quantification of HRP-labeled LMC $C_{L}$ neurons as a percentage of all HRP-labeled LMC neurons. Numbers of embryos analyzed: $n=4$ for GFP and EphA4::GFP. Minimum number of HRP ${ }^{+}$neurons counted per embryo: 109. ${ }^{*} p<0.05$.

Wichterle et al., 2002; Grunwald et al., 2004; Herrmann et al., 2010). All the mutants were maintained in a comparable mixed $129 /$ Svev $\times$ C57BL/6 background. Fertilized chick eggs (Couvoir Simetin) were stored for a maximum of 1 week at $18^{\circ} \mathrm{C}$, incubated at $38^{\circ} \mathrm{C}$, and staged according to standard protocols (Hamburger and Hamilton, 1951). Embryos used were of either sex.

Dissociated motor neuron cultures and turning assay. Dissociated motor neuron cultures were prepared, and turning assay was performed as described previously (Dudanova et al., 2010). EphA-Fc chimeric proteins (R\&D Systems) and human IgG Fc-fragment (Jackson Immunoresearch)

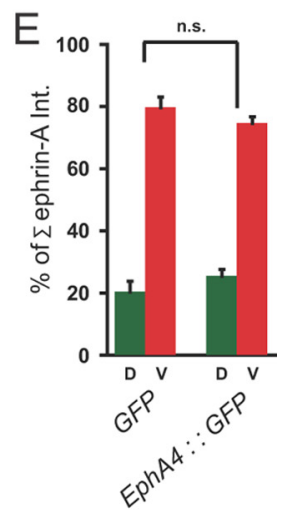

were preclustered with anti-human Fc antibodies (Jackson Immunoresearch) at a 5:1 ratio for $1 \mathrm{~h}$ at room temperature (RT). Phosphatidylinositolspecific phospholipase C (PI-PLC; $1 \mathrm{U} / \mathrm{ml}$, Sigma) was added for $1 \mathrm{~h}$ before the assay.

Chick in ovo electroporation. Chick limb electroporations were performed as described previously (Luria et al., 2008).

Retrograde neuronal fills. Retrograde fills in chick embryos were performed as described previously (Kao and Kania, 2011). E12.5 mouse embryos were eviscerated and kept in DMEM/F-12 medium (Invitrogen) aerated with $5 \% \mathrm{CO}_{2} / 95 \%$ $\mathrm{O}_{2}$. A 6\% lysine-fixable tetramethylrhodaminedextran (molecular weight 3000, Invitrogen) solution in PBS with $0.4 \%$ Triton X-100 was injected into the ventral shank and allowed to diffuse for 5-6 h at RT. Embryos with labeling in the dorsal nerve were excluded from analysis.

Biochemistry. SDS-PAGE was performed as described previously (Dudanova et al., 2010). The following primary antibodies were used: mouse monoclonal anti-EphA4 (anti-Sek, BD Biosciences), 1:1000; and mouse monoclonal anti-tubulin (clone DM 1A, Sigma), 1:50,000.

Immunostaining. Ephrin/Eph-Fc overlays were performed as described previously (Kao and Kania, 2011). For immunostaining, embryos were fixed in $4 \%$ paraformaldehyde in $0.1 \mathrm{M}$ phosphate buffer for $1-1.5 \mathrm{~h}$ at $4^{\circ} \mathrm{C}$ and cryoprotected in 30\% sucrose, and 15-25 $\mu \mathrm{m}$ transverse cryosections were made. The sections were dried, rehydrated in PBS, and incubated in blocking solution ( $4 \%$ goat serum, $4 \%$ donkey serum, $2 \%$ bovine serum albumin in PBS) with $0.3 \%$ Triton $\mathrm{X}-100$ overnight at $4^{\circ} \mathrm{C}$. Primary antibodies were applied in blocking solution with $0.1 \%$ Triton X-100 for 2-4 h at RT, followed by Cy2-, Cy3-, or Cy5-conjugated secondary antibodies (Jackson Immunoresearch) for $2 \mathrm{~h}$ at RT. Immunostaining of motor neuron cultures and HeLa cells was performed as described previously (Dudanova et al., 2010). The following primary antibodies were used: rabbit anti-EphA4 (S20, Santa Cruz Biotechnology), 1:300; mouse anti-neurofilament 160 (clone NN18, Sigma), 1:500; mouse antiIslet1 (39.4D5, Developmental Studies Hybridoma Bank), 1:50; rabbit anti-Lim1 (gift from A. Huber-Brösamle, Helmholtz Center Munich, Munich, Germany), 1:800; rabbit anti-GFP (Invitrogen), 1:2000; and rat anti-HA (Roche), 1:2000. Embryo sections with retrograde tracings were examined with a Leica SP2 confocal microscope. All other immunostainings were examined with an Axioplan epifluorescent microscope (Zeiss) and were documented with MetaMorph software.

Statistical analysis. Data are shown as the mean \pm SEM, and the $t$ test was used to analyze statistical significance.

\section{Results}

EphA:ephrinA reverse signaling mediates attractive turning responses in $\mathrm{LMC}_{\mathrm{L}}$ axons

To investigate whether EphAs can act as chemoattractants in an acute turning assay, dissociated primary lumbar LMC neurons from E12.5 Hb9-GFP transgenic mouse embryos (Wichterle et al., 2002) were exposed to a linear gradient of preclustered 

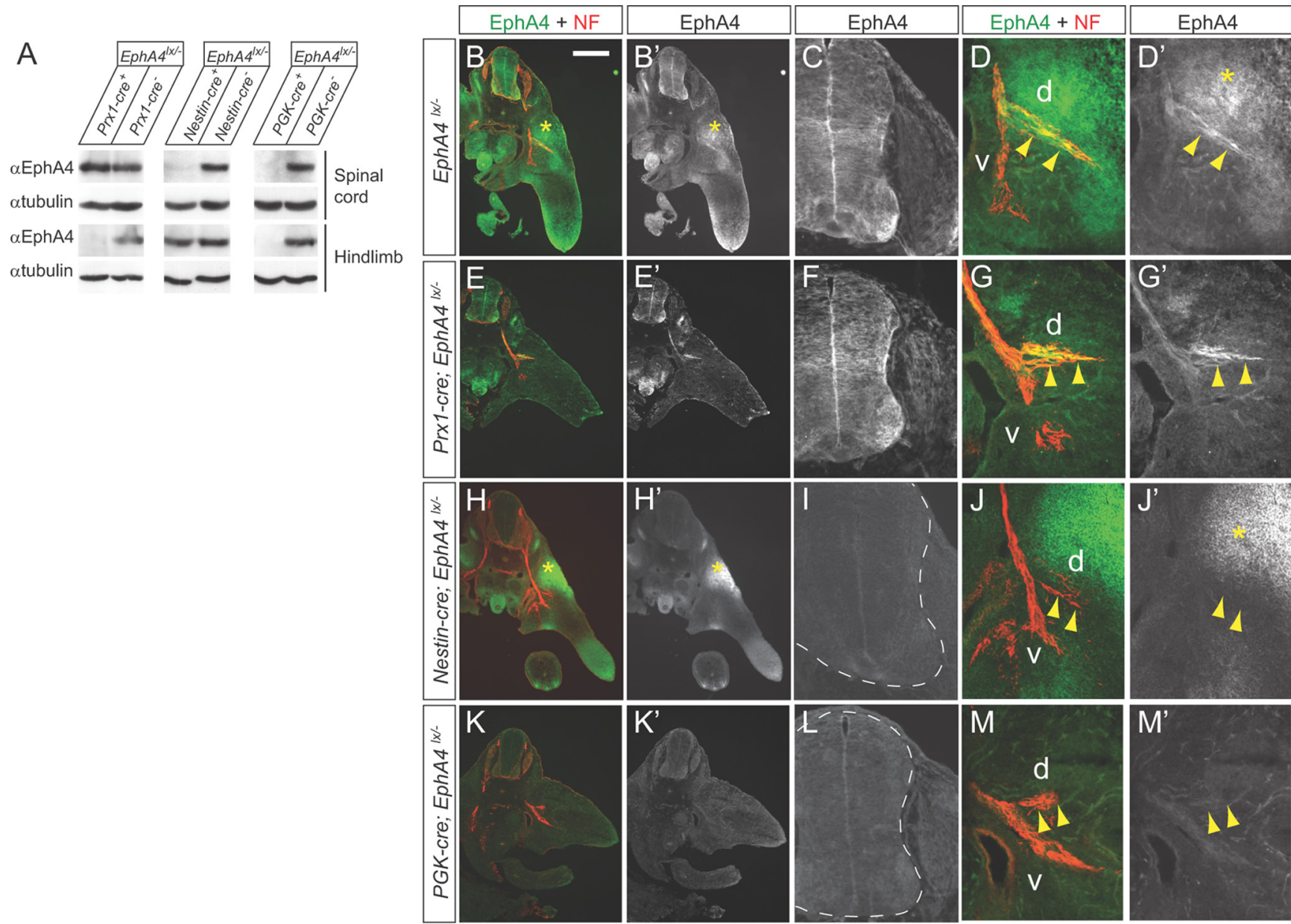

Figure 3. EphA4 expression in conditional EphA4 mutants. A, Representative Western blots of spinal cord and hindlimb lysates from E12.5 embryos showing complete removal of EphA4 protein from the hindlimb in PrxT-cre;EphA4 ${ }^{\mid x /}$ embryos, from the spinal cord in Nestin-cre; EphA4 ${ }^{\mid x /-}$ embryos, and from both tissues in PGK-cre;EphA4 ${ }^{\mid x /}$ embryos. $\alpha$-Tubulin is shown as loading control. $\boldsymbol{B}-\boldsymbol{M}$, Cross sections of E11.5 embryos of the indicated genotypes labeled with anti-EphA4 and anti-NF antibodies. $\boldsymbol{B}, \boldsymbol{E}, \boldsymbol{H}, \boldsymbol{K}$, overviews; $\boldsymbol{C}, \boldsymbol{F}, \boldsymbol{I}, \boldsymbol{L}$, staining in the spinal cord; $\boldsymbol{D}, \boldsymbol{G}, \boldsymbol{J}, \boldsymbol{M}$, staining in the hindlimb. Dashed lines indicate the contours of the spinal cord. d, Dorsal nerve branch; $\boldsymbol{v}$, ventral nerve branch. Asterisks in $\boldsymbol{B}^{\prime}, \boldsymbol{D}^{\prime}, \boldsymbol{H}^{\prime}$, and $\boldsymbol{J}^{\prime}$ mark the domain of EphA4 expression in the dorsal limb. Arrowheads point to the dorsal nerve branch. Scale bar: (in $\boldsymbol{B}$ ), overviews, $400 \mu \mathrm{m}$; higher-power magnifications, $100 \mu \mathrm{m}$.

EphA-Fc fusion proteins in the Dunn chamber (Yam et al., 2009; Dudanova et al., 2010). No turning was observed in a control Fc gradient (average turning angle $\beta=0.7 \pm 2.5^{\circ}$ ) (Fig. $1 A-C, F$ ). Application of EphA4-Fc resulted in attractive turning of motor axons $\left(\beta=9.4 \pm 2.8^{\circ}\right.$ for $1 \mu \mathrm{g} / \mathrm{ml} \mathrm{EphA} 4-\mathrm{Fc}$ and $12.5 \pm 3.1^{\circ}$ for $10 \mu \mathrm{g} / \mathrm{ml}$ EphA4-Fc) (Fig. $1 A-C, G, H$ ). In addition, EphA7, another EphA protein enriched in the dorsal limb (Araujo et al., $1998)$, induced attractive turning with similar strength $(\beta=$ $9.7 \pm 3.4^{\circ}$ for $1 \mu \mathrm{g} / \mathrm{ml}$ EphA4-Fc and $13.4 \pm 2.7^{\circ}$ for $10 \mu \mathrm{g} / \mathrm{ml}$ EphA4-Fc) (Fig. 1 A-C,I,J). The average speed of axon growth was comparable in all conditions (Fig. $1 D$ ).

To determine the divisional identity of the LMC neurons that responded to EphA-Fc gradients, we monitored the expression of the $\mathrm{LMC}_{\mathrm{M}}$ marker Islet1 (Tsuchida et al., 1994). The average turning angles of $\mathrm{LMC}_{\mathrm{L}}$, but not $\mathrm{LMC}_{\mathrm{M}}$ axons, were significantly different between control and EphA gradients (Fig. 1A,E). The higher turning angles observed for $\mathrm{LMC}_{\mathrm{M}}$ neurons in response to EphA4 were not significantly different from control, and are likely due to the ability of EphA4 to bind ephrinBs, which are expressed in $\mathrm{LMC}_{\mathrm{M}}$ neurons (Luria et al., 2008) and can mediate attractive reverse signaling (Kao and Kania, 2011). These data demonstrate that EphA proteins induce rapid attractive turning of $\mathrm{LMC}_{\mathrm{L}}$ axons, consistent with the growth of these axons toward the EphA4-expressing limb mesenchyme in vivo.
To test whether the turning response to EphAs is mediated by axonal ephrinAs, we treated the cultures with PI-PLC, which removes glycosyl phosphatidylinositol (GPI)-anchored proteins from cell surface (Marquardt et al., 2005) (Fig. $1 \mathrm{~K}$ ). The addition of PI-PLC completely abolished turning in an EphA7-Fc gradient (Fig. $1 L$ ), suggesting that the attractive response to EphAs is mediated by ephrinA reverse signaling.

\section{Ectopic expression of EphA4 in limb mesenchyme is sufficient to redirect $\mathrm{LMC}_{\mathrm{L}}$ projections}

We reasoned that if $\mathrm{LMC}_{\mathrm{L}}$ axons are attracted to EphA4 in the dorsal limb, then expression of EphA4 in the ventral limb should attract some $\mathrm{LMC}_{\mathrm{L}}$ axons into the ventral nerve. To test this idea, EphA4::GFP or GFP control plasmids were introduced into chick hindlimbs at Hamburger-Hamilton (HH) stage $18 / 19$ by in ovo electroporation (Fig. $2 \mathrm{~A}$ ), leading to ectopic patches of EphA4::GFP or GFP-only expression in the ventral limb (Fig. $\left.2 B, B^{\prime}, C, C^{\prime}, D\right)$. To detect misprojecting $\mathrm{LMC}_{\mathrm{L}}$ neurons, we injected horseradish peroxidase (HRP) into the ventral shank of HH stage 28/29 embryos, and monitored LMC expression of the $\mathrm{LMC}_{\mathrm{L}}$ marker Lim1 (Tsuchida et al., 1994). Significantly more $\mathrm{LMC}_{\mathrm{L}}$ neurons innervated the ventral limb in embryos overexpressing EphA4::GFP (14 $\pm 4 \%$ of all $\mathrm{HRP}^{+}$neurons) than in controls $(4 \pm 3 \%$ ) (Fig. $2 F-H)$. The distribution of free net eph- 

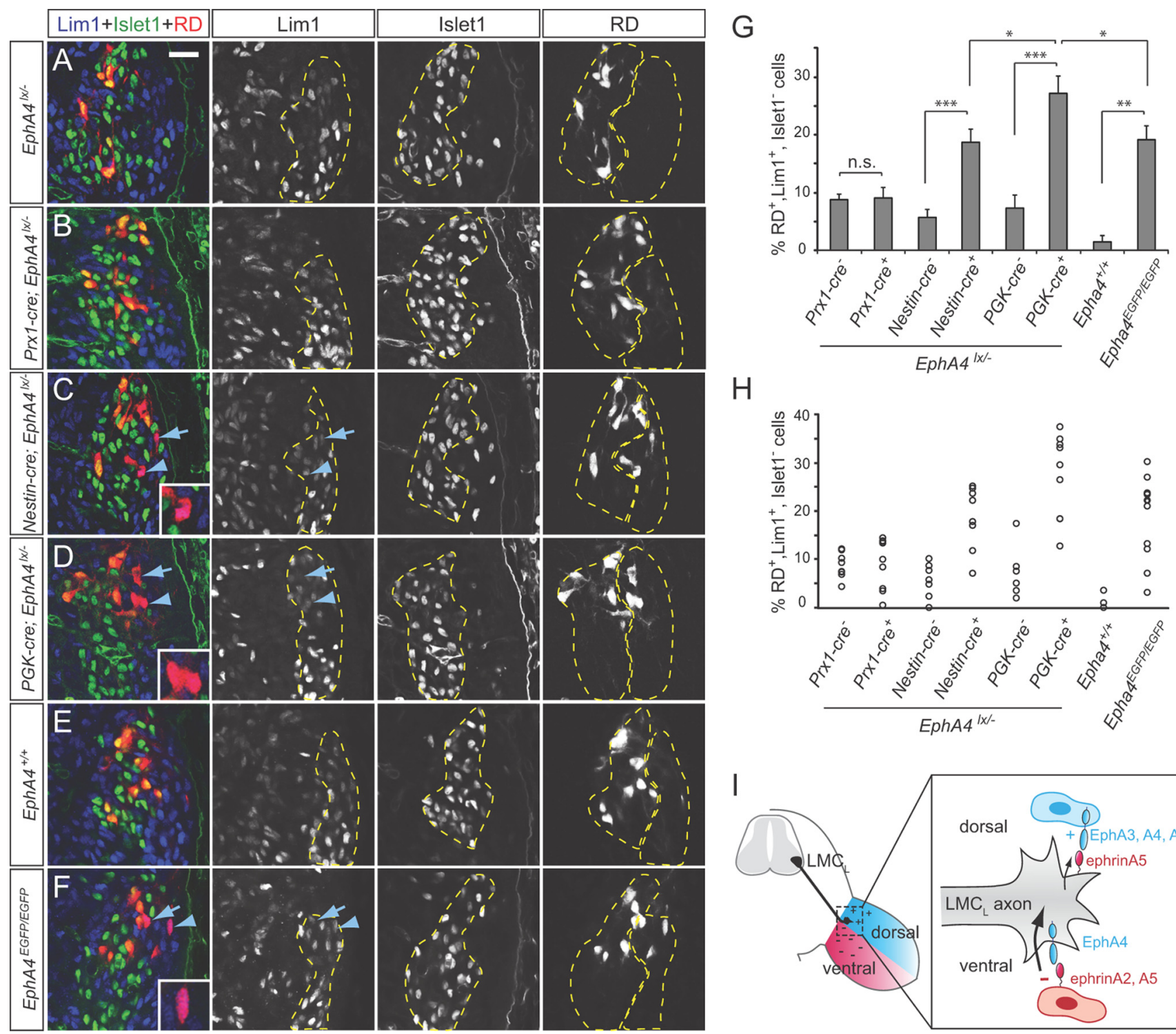

$\mathrm{H}$
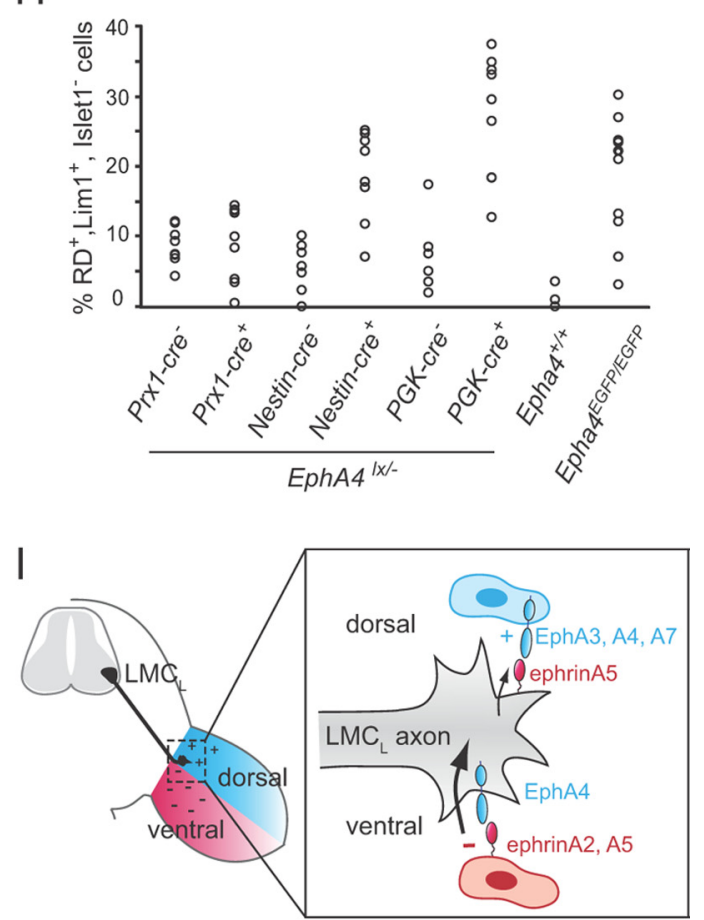

Figure 4. Guidance errors in EphA4 mutants. $\boldsymbol{A}-\boldsymbol{F}$, Single confocal plane images of the spinal cord of the indicated genotypes after ventral RD injections and staining for Islet 1 and Lim1. Arrows and arrowheads point to Islet $1^{-}, \mathrm{Lim} 1^{+} \mathrm{LMC} C_{\mathrm{L}}$ neurons labeled with $\mathrm{RD}$. Examples indicated by arrowheads are shown in the insets at higher magnification. Dashed lines indicate $L M C_{M}$ and $L M C_{L}$

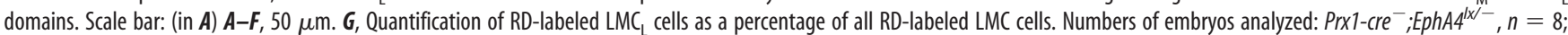

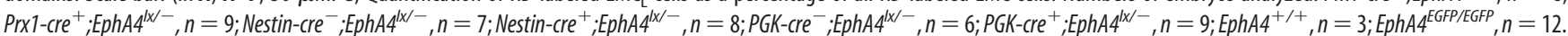
Minimum number of $\mathrm{RD}^{+}$cells counted per embryo: 106. ${ }^{*} p<0.05,{ }^{* *} p<0.01,{ }^{* * *} p<0.001$. $\boldsymbol{H}$, Scatter plots of individual values from each embryo. I, Model of LMC $\mathrm{L}$ axon guidance by EphA forward and ephrinA reverse signaling. EphrinAs expressed ventrally act as repellants, triggering forward EphA4 signaling in the axon (thick arrow), while EphAs expressed dorsally act as weak attractants, eliciting reverse ephrinA signaling (thin arrow).

rinAs appeared unchanged upon EphA4::GFP overexpression (Fig. $2 B^{\prime \prime}, C^{\prime \prime}, E$ ); therefore, $\mathrm{LMC}_{\mathrm{L}}$ axon misrouting was not due to EphA4::GFP masking repulsive ephrinAs in the ventral mesenchyme. Thus, the redirection of $\mathrm{LMC}_{\mathrm{L}}$ axons by ectopic EphA4 is likely mediated by attractive ephrinA reverse signaling.

\section{The contribution of mesenchymal EphA4 to LMC axon guidance}

If mesenchymal EphA4 contributes to $\mathrm{LMC}_{\mathrm{L}}$ axon guidance, we expected that (1) genetic deletion of EphA4 in the hindlimb should produce $\mathrm{LMC}_{\mathrm{L}}$ pathfinding errors, and (2) ablating EphA4 only in motor neurons should result in a weaker phenotype compared with a general EphA4 knockout. To test these predictions, we generated limb-specific and nervous systemspecific EphA4 knockouts by crossing the conditional EphA4 ${ }^{l x}$ line (Herrmann et al., 2010) with Prx1-cre and Nestin-cre transgenic mice (Tronche et al., 1999; Logan et al., 2002). In addition, $E p h A 4^{l x / l x}$ mice were crossed with a ubiquitous deleter line, $P G K$ cre, to obtain EphA4-null mutants. Control EphA4 $4^{l x / l x}$ embryos had unaltered amounts of EphA4 protein and did not display guidance errors in the hindlimb (Herrmann et al., 2010; and data not shown). In all experiments with conditional knockouts, $\mathrm{cre}^{+} ; E p h A 4^{i x /-}$ embryos were compared with $\mathrm{cre}^{-} ; E p h A 4^{l x /-}$ littermates.

Western blot and immunohistochemical analyses confirmed the absence of EphA4 protein in the hindlimbs of Prx1-cre; $E p h A 4^{l x /-}$ embryos, and in the spinal cords and dorsal limb nerves of Nestin-cre;EphA4 ${ }^{l x /-}$ mutants (Fig. $3 A-J$ ). In PGK-cre; $E p h A 4^{l x /-}$ embryos, no EphA4 protein was present in any tissue (Fig. $3 A, K-M$ ). To assess $\mathrm{LMC}_{\mathrm{L}}$ projection fidelity in the mu- 
tants, we monitored Islet 1 and Lim 1 expression in LMC neurons labeled by rhodamine dextran (RD) injections into the ventral limb. In EphA $4^{l x /-}$ control embryos, the number of RD-labeled $\mathrm{LMC}_{\mathrm{L}}$ neurons was low (5-8\% of all $\mathrm{RD}^{+}$LMC neurons) (Fig. $4 A, G, H)$. Some $\mathrm{LMC}_{\mathrm{L}}$ misprojections in these controls could be due to the reduced amount of EphA4 protein in heterozygous $E p h A 4^{l x /-}$ embryos compared with EphA $4^{l x / l x}$ and wild-type embryos (compare to EphA4 ${ }^{+/+}$controls; data not shown). In Prx1cre; EphA $4^{l x /-}$ embryos, the numbers of ventrally projecting $\mathrm{LMC}_{\mathrm{L}}$ neurons were not different from control littermates $(9.1 \pm$ $1.8 \%$ ) (Fig. $4 B, G, H$ ), indicating that further removal of EphA4 from the hindlimb does not have a strong impact on axon guidance. In contrast, in Nestin-cre;EphA $4^{l x /-}$ mutants, the fraction of $\mathrm{RD}$-labeled $\mathrm{LMC}_{\mathrm{L}}$ neurons was $18.7 \pm 2.3 \%$ and significantly higher than in controls (Fig. $4 C, G, H$ ), consistent with a critical role of axonal EphA4 in $\mathrm{LMC}_{\mathrm{L}}$ axon pathfinding (Helmbacher et al., 2000; Eberhart et al., 2002; Luria et al., 2008). Interestingly, the $\mathrm{LMC}_{\mathrm{L}}$ error rate in these embryos was significantly lower than in PGK-cre;EphA4 $4^{l x /-}$ embryos (27.2 $\pm 2.9 \%$ ) (Fig. $4 D, G, H$ ), indicating that when EphA4 is absent from motor neurons only, some $\mathrm{LMC}_{\mathrm{L}}$ axons are guided correctly by limb-derived EphA4. These results reveal a significant role for mesenchymal EphA4 in attracting motor axons.

\section{Forward signaling-deficient EphA4 partially rescues LMC guidance errors}

To further explore the contribution of EphA4:ephrinA reverse signaling to LMC axon guidance in vivo, we took advantage of the EphA4 ${ }^{E G F P}$ mouse line (Grunwald et al., 2004), in which the intracellular domains of EphA4 are replaced by EGFP, making the receptor signaling incompetent, while it retains its ability to bind ephrins and trigger reverse signaling (Grunwald et al., 2004; Filosa et al., 2009). The expression levels of EphA4-EGFP protein were similar to the wild-type isoform (Grunwald et al., 2004; and data not shown). Retrograde tracings revealed a high number of $\mathrm{LMC}_{\mathrm{L}}$ axons in the ventral limbs of EphA4 ${ }^{\text {EGFP/EGFP }}$ mutants $\left(19.1 \pm 2.4 \%\right.$ of all $\mathrm{RD}^{+}$neurons $)$compared with EphA4 ${ }^{+/+}$ littermates $(1.5 \pm 1.1 \%$ ) (Fig. $4 E-H)$, confirming an important role of forward signaling in this pathway choice. However, the fraction of misguided $\mathrm{LMC}_{\mathrm{L}}$ neurons was significantly lower than in PGK-cre;EphA $4^{l x /-}$ knockouts $(27.2 \pm 2.9 \%$ ) (Fig. $4 D, G, H$ ), indicating that intact EphA4 extracellular domain is sufficient to rescue some of the $\mathrm{LMC}_{\mathrm{L}}$ guidance errors, most likely by activating ephrinA reverse signaling.

\section{Discussion}

Our genetic experiments demonstrate a contribution of both forward and Eph:ephrin reverse signaling to the establishment of limb innervation. EphA4 forward signaling appears to be the "dominant" guidance system for the dorsal/ventral pathway choice, because genetic ablation of EphA4 expression in motor neurons had a stronger impact on axon pathfinding than its deletion from the limb. The effects of EphA4 ablation in the hindlimb may, however, be partially compensated by other EphA proteins. While EphA4 is the main EphA receptor on $\mathrm{LMC}_{\mathrm{L}}$ axons, dorsal limb mesenchyme also expresses EphA7 (Araujo et al., 1998; Krawchuk and Kania, 2008) and EphA3 (Iwamasa et al., 1999). Therefore, partial removal of chemoattractive cues from the dorsal limb of Prx 1 -cre;EphA $4^{l x /-}$ mice would not have a large impact on the LMC axon projection fidelity when EphA4 forward signaling in motor axons is intact (Fig. 4I). However, with EphA4 forward repulsion eliminated, LMC axons might rely on attractive cues to a greater extent, and the deletion of one limb-derived
EphA would have a more pronounced effect on pathway selection. Indeed, we observed a significant difference in the number of $\mathrm{LMC}_{\mathrm{L}}$ misprojections between the full EphA4 knockout, on the one side, and the nervous system knockout and forward signaling-deficient mutant, on the other. In fact, this difference was unexpectedly large, considering the remaining expression of other EphAs in the hindlimb. Our new findings on the function of ephrinA reverse signaling in motor axons extend previous observations in other systems where the role of reverse signaling has been demonstrated genetically. For instance, reverse signaling is required for the guidance of retinotectal (Rashid et al., 2005), vomeronasal (Knöll et al., 2001), and olfactory sensory projections (Cutforth et al., 2003), and mediates axon-axon interactions in spinal sensory-motor circuits (Wang et al., 2011). Moreover, a recent study by Bonanomi et al. (2012) provided independent and complementary evidence for a requirement for ephrinA reverse signaling in LMC axon guidance. In contrast to our findings (Dudanova et al., 2010, and this study), Bonanomi et al. (2012) reported that EphAs and GDNF alone lack chemoattractive activity and are only able to attract LMC motor axons when added in combination. This discrepancy may be due to methodological differences. While Bonanomi et al. (2012) analyzed a mixed population of all lumbar LMC axons, we used only the lower half of the LMC, which is affected in vivo, and distinguished between $\mathrm{LMC}_{\mathrm{L}}$ and $\mathrm{LMC}_{\mathrm{M}}$ turning responses.

Together with the work of Bonanomi et al. (2012), our present findings firmly establish parallel reverse and forward signaling as an important mode of Eph/ephrin function. Several questions remain unanswered. Do EphA4 receptors in limb mesenchymal cells become activated upon engagement with ephrinAs on motor axons, and do these cells respond to EphA4 forward signaling? And what prevents motor axons from adhering to EphA4positive mesenchymal cells, a process that could interfere with their further growth? One possibility is that EphA ectodomains are proteolytically cleaved (Inoue et al., 2009; Oricchio et al., 2011). Cleavage would eventually terminate EphA forward signaling in mesenchymal cells and allow motor axons to continue growing into the limb.

\section{References}

Araujo M, Piedra ME, Herrera MT, Ros MA, Nieto MA (1998) The expression and regulation of chick EphA7 suggests roles in limb patterning and innervation. Development 125:4195-4204.

Bonanomi D, Chivatakarn O, Bai G, Abdesselem H, Lettieri K, Marquardt T, Pierchala BA, Pfaff SL (2012) Ret is a multifunctional coreceptor that integrates diffusible- and contact-axon guidance signals. Cell 148:568-582

Cutforth T, Moring L, Mendelsohn M, Nemes A, Shah NM, Kim MM, Frisén J, Axel R (2003) Axonal ephrin-As and odorant receptors: coordinate determination of the olfactory sensory map. Cell 114:311-322.

Dickson BJ (2002) Molecular mechanisms of axon guidance. Science 298:1959-1964

Dudanova I, Gatto G, Klein R (2010) GDNF acts as a chemoattractant to support ephrinA-induced repulsion of limb motor axons. Curr Biol 20:2150-2156.

Eberhart J, Swartz M, Koblar SA, Pasquale EB, Tanaka H, Krull CE (2000) Expression of EphA4, ephrin-A2 and ephrin-A5 during axon outgrowth to the hindlimb indicates potential roles in pathfinding. Dev Neurosci 22:237-250

Eberhart J, Swartz ME, Koblar SA, Pasquale EB, Krull CE (2002) EphA4 constitutes a population-specific guidance cue for motor neurons. Dev Biol 247:89-101.

Egea J, Klein R (2007) Bidirectional Eph-ephrin signaling during axon guidance. Trends Cell Biol 17:230-238.

Filosa A, Paixão S, Honsek SD, Carmona MA, Becker L, Feddersen B, Gaitanos L, Rudhard Y, Schoepfer R, Klopstock T, Kullander K, Rose CR, 
Pasquale EB, Klein R (2009) Neuron-glia communication via EphA4/ ephrin-A3 modulates LTP through glial glutamate transport. Nat Neurosci 12:1285-1292.

Grunwald IC, Korte M, Adelmann G, Plueck A, Kullander K, Adams RH, Frotscher M, Bonhoeffer T, Klein R (2004) Hippocampal plasticity requires postsynaptic ephrinBs. Nat Neurosci 7:33-40.

Hamburger V, Hamilton HL (1951) A series of normal stages in the development of the chick embryo. J Morphol 88:49-92.

Helmbacher F, Schneider-Maunoury S, Topilko P, Tiret L, Charnay P (2000) Targeting of the EphA4 tyrosine kinase receptor affects dorsal/ventral pathfinding of limb motor axons. Development 127:3313-3324.

Herrmann JE, Pence MA, Shapera EA, Shah RR, Geoffroy CG, Zheng B (2010) Generation of an EphA4 conditional allele in mice. Genesis 48:101-105.

Inoue E, Deguchi-Tawarada M, Togawa A, Matsui C, Arita K, KatahiraTayama S, Sato T, Yamauchi E, Oda Y, Takai Y (2009) Synaptic activity prompts gamma-secretase-mediated cleavage of EphA4 and dendritic spine formation. J Cell Biol 185:551-564.

Iwamasa H, Ohta K, Yamada T, Ushijima K, Terasaki H, Tanaka H (1999) Expression of Eph receptor tyrosine kinases and their ligands in chick embryonic motor neurons and hindlimb muscles. Dev Growth Differ 41:685-698.

Kania A, Jessell TM (2003) Topographic motor projections in the limb imposed by LIM homeodomain protein regulation of ephrin-A:EphA interactions. Neuron 38:581-596.

Kao TJ, Kania A (2011) Ephrin-mediated cis-attenuation of Eph receptor signaling is essential for spinal motor axon guidance. Neuron 71:76-91.

Knöll B, Zarbalis K, Wurst W, Drescher U (2001) A role for the EphA family in the topographic targeting of vomeronasal axons. Development 128:895-906.

Krawchuk D, Kania A (2008) Identification of genes controlled by LMX1B in the developing mouse limb bud. Dev Dyn 237:1183-1192.

Kullander K, Mather NK, Diella F, Dottori M, Boyd AW, Klein R (2001) Kinase-dependent and kinase-independent functions of EphA4 receptors in major axon tract formation in vivo. Neuron 29:73-84.

Lallemand Y, Luria V, Haffner-Krausz R, Lonai P (1998) Maternally ex- pressed PGK-Cre transgene as a tool for early and uniform activation of the Cre site-specific recombinase. Transgenic Res 7:105-112.

Landmesser L (1978) The distribution of motoneurones supplying chick hind limb muscles. J Physiol 284:371-389.

Logan M, Martin JF, Nagy A, Lobe C, Olson EN, Tabin CJ (2002) Expression of Cre Recombinase in the developing mouse limb bud driven by a Prxl enhancer. Genesis 33:77-80.

Luria V, Krawchuk D, Jessell TM, Laufer E, Kania A (2008) Specification of motor axon trajectory by ephrin-B:EphB signaling: symmetrical control of axonal patterning in the developing limb. Neuron 60:1039-1053.

Marquardt T, Shirasaki R, Ghosh S, Andrews SE, Carter N, Hunter T, Pfaff SL (2005) Coexpressed EphA receptors and ephrin-A ligands mediate opposing actions on growth cone navigation from distinct membrane domains. Cell 121:127-139.

Oricchio E, Nanjangud G, Wolfe AL, Schatz JH, Mavrakis KJ, Jiang M, Liu X, Bruno J, Heguy A, Olshen AB, Socci ND, Teruya-Feldstein J, Weis-Garcia F, Tam W, Shaknovich R, Melnick A, Himanen JP, Chaganti RS, Wendel HG (2011) The eph-receptor a7 is a soluble tumor suppressor for follicular lymphoma. Cell 147:554-564.

Rashid T, Upton AL, Blentic A, Ciossek T, Knöll B, Thompson ID, Drescher U (2005) Opposing gradients of ephrin-As and EphA7 in the superior colliculus are essential for topographic mapping in the mammalian visual system. Neuron 47:57-69.

Tronche F, Kellendonk C, Kretz O, Gass P, Anlag K, Orban PC, Bock R, Klein R, Schütz G (1999) Disruption of the glucocorticoid receptor gene in the nervous system results in reduced anxiety. Nat Genet 23:99-103.

Tsuchida T, Ensini M, Morton SB, Baldassare M, Edlund T, Jessell TM, Pfaff SL (1994) Topographic organization of embryonic motor neurons defined by expression of LIM homeobox genes. Cell 79:957-970.

Wang L, Klein R, Zheng B, Marquardt T (2011) Anatomical coupling of sensory and motor nerve trajectory via axon tracking. Neuron 71:263-277.

Wichterle H, Lieberam I, Porter JA, Jessell TM (2002) Directed differentiation of embryonic stem cells into motor neurons. Cell 110:385-397.

Yam PT, Langlois SD, Morin S, Charron F (2009) Sonic hedgehog guides axons through a noncanonical, Src-family-kinase-dependent signaling pathway. Neuron 62:349-362. 